\title{
PENGAJARAN BAHASA YANG BERKARAKTER KEBANGSAAN DAN BERPERSPEKTIF MULTIBUDAYA DALAM ERA GLOBALISASI
}

\author{
Rosida Tiurma Manurung \\ Dosen Tetap UK Maranatha Bandung \\ Jalan Prof. drg. Suria Sumantri No. 65 Bandung - 40164 \\ Telp. 62-22-2012186 ext. 957/ Fax. 62-22-2015154 \\ E-mail: rosidatm@gmail.com
}

\begin{abstract}
ABSTRAK. Merupakan satu kenyataan bahwa masyarakat Indonesia itu multietnis, multiagama, multikutural, atau multibudaya. Keragaman atau keberbedaan itu merupakan kenyataan yang harus diterima. Dalam masyarakat multibudaya, keberbedaan itu dapat menimbulkan pertikaian atau perpecahan. Oleh sebab itu, diperlukan suatu upaya agar keberbedaan itu justru dapat menumbuhkembangkan rasa bangga dan cinta kepada bangsa dan negara karena bangsa kita memiliki kekayaan dan keunikan budaya yang sangat luar biasa dan keberbedaan itu dapat pula menjadi alat untuk menciptakan insan yang memiliki karakter kebangsaan. Hal tersebut menjadi sangat penting mengingat derasnya arus globalisasi dan bebasnya unsur budaya luar yang melenggang memasuki wilayah kita. Dengan demikian, diperlukan suatu upaya untuk memperkukuh rasa kebangsaan. Salah satunya adalah dengan pengajaran bahasa yang berkarakter kebangsaan. Karakter kebangsaan yang tinggi dapat secara dinamis digunakan untuk mengatasi ancaman, kendala, atau tantangan yang datang dari luar yang dapat mengancam kelangsungan hidup dan keutuhan bangsa. Untuk mewujudkan insan yang berkarakter kebangsaan dalam masyarakat multibudaya, diperlukan revitalisasi pendidikan yang diarahkan kepada perspektif multibudaya. Pendidikan dapat dijadikan alat yang mampu menuntun peserta didik menjadi manusia yang berperilaku dan berakhlak baik sekaligus memiliki karakter kebangsaan yang kuat. Pengajaran bahasa dapat dijadikan motor untuk mengimplementasikan pendidikan yang berperspektif multibudaya, yaitu pendidikan yang memiliki visi dan misi untuk menghargai keberbedaan atau pluralitas, demokrasi, humanisme, dan mengembangkan karakter kebangsaan. Pengajaran bahasa perlu direvitalisasi agar mampu membuat siswa menjadi insan yang menjunjung tinggi moralitas, kedisiplinan, keadilan, kesetaraan, kepedulian sosial, integritas, tanggung jawab, serta cinta kepada tanah air dalam perilakunya sehari-hari. Guru pun dianggap memiliki power untuk mengubah dan merevitalisasi pengajaran bahasa yang konvensional menjadi pengajaran bahasa yang berkarakter kebangsaan dan berperspektif multibudaya.
\end{abstract}

Kata Kunci: peran guru, revitalisasi pendidikan, karakter kebangsaan, multibudaya 


\title{
LANGUAGE LEARNING WITH NATIONAL CHARACTER AND MULTICULTURAL PERSPECTIVE IN GLOBALIZATION ERA
}

\begin{abstract}
It ias a verity that Indonesia is a multiethnic, multireligious, multicultural nation. Diversity is a fact we must all accept. In a multicultural society, such differences are potential to bring about conflict or disintegration. For that reason, it is necessary to make efforts to make sure that such differences have positive impact on the community and make them proud of and have such great love to their incredible nation and state because this nation has abundant wealth and cultural uniqueness and such differences can also serve as instruments to create a person with strong national character. This is of great significance bearing in mind the strong wave of globalization and the unlimited entry of foreign cultural elements into the country. Therefore, we need to make efforts to strengthen our national character. Highly cultivated national character can be used is such dynamic way in order to deal with threats, constraints, or incoming challenges that can put serious threat on the sustainability and unity of the nation. In order to create a person with a strong national character in this multicultural community, it is required to have revitalization in education supported by multicultural perspective. Education can serve as a tool that is capable if directing students to become a person with good behavior and faith and at the same time having strong national character. We can use language learning as a drive to implement education with multicultural perspective, i.e. education with vision and mission of appreciating plurality, democracy, humanism, and national-character building. Language learning need to be revitalized in order to turn students into person who highly appreciate morality, discipline, fairness, equality, social awareness, integrity, responsibility and the love for their mother land in their daily attitude. Teachers are alco considered having such power to change and revitalize conventional language learning into language learning with national character and multicultural perspective.
\end{abstract}

Keywords: teacher's role, education revitalization, national character, multiculture

\section{PENDAHULUAN}

Pada saat ini, globalisasi sudah melanda dunia, termasuk Indonesia. Implikasi yang ditimbulkannya semakin dirasakan dalam setiap sisi kehidupan. Semua aktivitas yang semula terbatas pada skala nasional, kini mulai bergeser pada skala internasional yang jangkauannya tidak terbatas. Globalisasi budaya melalui media televisi dan internet telah memengaruhi gaya hidup dan budaya bangsa kita.

Globalisasi yang menggunakan berbagai media informasi canggih, khususnya melalui proses digitalisasi, telah menyebabkan berbagai pesan, kreasi, peristiwa, tayangan, atau pikiran merebak dengan cepat dan memengaruhi kontruksi berpikir masyarakat Indonesia. Kita tidak pernah membayangkan sebelumnya bahwa masyarakat Indonesia akan diinternasionalisasi, termasuk masyarakat 
pedesaan. Sangat disayangkan, proses globalisasi berjalan sepihak saja. Oleh karena itu, untuk menghadapi tantangan global yang sudah sedemikian kompleks dan berkembang dengan cepat, diperlukan ide-ide segar yang dapat dikembangkan dalam konteks kultural Indonesia. Dengan demikian, budaya Indonesia dan karakter kebangsaan dapat dipertahankan. Jadi, diperlukan suatu upaya untuk memperkukuh rasa kebangsaan. Salah satunya adalah dengan pengajaran bahasa yang berkarakter kebangsaan. Karakter kebangsaan yang tinggi dapat secara dinamis digunakan untuk mengatasi ancaman, kendala, atau tantangan yang datang dari luar yang dapat mengancam kelangsungan hidup dan keutuhan bangsa.

Untuk mewujudkan insan yang berkarakter kebangsaan dalam masyarakat multibudaya, diperlukan revitalisasi pendidikan yang diarahkan kepada perspektif multibudaya. Pendidikan dapat dijadikan alat yang mampu menuntun peserta didik menjadi manusia yang berperilaku dan berakhlak baik sekaligus memiliki karakter kebangsaan yang kuat. Pengajaran bahasa dapat dijadikan motor untuk mengimplementasikan pendidikan yang berperspektif multibudaya, yaitu pendidikan yang memiliki visi dan misi untuk menghargai keberbedaan atau pluralitas, demokrasi, humanisme, dan mengembangkan karakter kebangsaan. Pengajaran bahasa perlu direvitalisasi agar mampu membuat siswa menjadi insan yang menjunjung tinggi moralitas, kedisiplinan, keadilan, kesetaraan, kepedulian sosial, integritas, tanggung jawab, serta cinta kepada tanah air dalam perilakunya sehari-hari. Guru pun dianggap memiliki power untuk mengubah dan merevitalisasi pengajaran bahasa yang konvensional menjadi pengajaran bahasa yang berkarakter kebangsaan dan berperspektif multibudaya.

\section{PEMBAHASAN}

\section{Peran Guru}

Peran guru dalam kegiatan belajar-mengajar bukanlah sekadar menjalankan proses tersebut secara mekanis berdasarkan ketentuan-ketentuan yang ada, tetapi guru merupakan orang yang harus melaksanakan tugas-tugasnya secara bertanggung jawab. Dalam pelaksanaannya, kinerja guru tidak bergantung pada tugas itu sendiri, tetapi bergantung pada sikap, cara berpikir, dan cara pandang guru terhadap tugas yang diembannya. Hill (1983) menyatakan, "the way in which our thinking is affected by presupposition, basic beliefs which constituted the staring points of person's thought." Jadi, cara berpikir manusia selalu bergantung pada presuposisi tertentu yang tidak dapat ditangkap oleh rasio, melainkan oleh kepercayaan. Bertitik tolak dari pernyataan tersebut, seorang guru harus memiliki pandangan terhadap lingkungan dan keilmuannya yang dapat diaplikasikan dalam pengajaran.

Guru berperan sebagai pendidik, sedangkan peserta didik berperan sebagai subjek didik. Keduanya merupakan insan yang kedudukannya sejajar dan berada dalam suatu interaksi, tetapi memiliki peran yang berbeda. Guru harus berperan sebagai penolong yang senatiasa berusaha memberi bantuan kepada peserta didik untuk mengembangkan dirinya dan membangun karakter secara utuh. Guru berdiri di antara peserta didik dan membagikan ilmunya secara total. Guru yang 
diperlengkapi dengan wawasan keilmuan dan pengalamannya harus dapat mengantarkan peserta didk kea rah pengembangan potensi, kepribadian, dan karakter yang lebih baik.

\section{Pendidikan Global dan Multibudaya}

Sebagai upaya untuk menjawab berbagai tantangan akibat perubahan yang cepat, diperlukan penyesuaian berupa revitalisasi pendidikan. Revitalisasi pendidikan merupakan sebuah tuntutan dalam era globalisasi. Flower dan Wright (1995) dalam tulisan Mustofa (2009) menyatakan bahwa pemahaman "global" sebagai "the goal of helping student see the world in non ethnocentric, non stereotypicalways with particular emphasis on elementary student he articulates and explo how to promote three traits of globally educated person: openmindedness, full mindedness." Justru, globalisasi harus dapat mengantarkan manusia kea rah akhlak dan perilaku yang lebih baik dan positif.

Bangsa Indonesia merupakan bangsa yang memiliki kekayaan nilai budaya yang beragam. Pada kenyataannya arus globalisasi telah membawa dampak terhadap nilai-nilai budaya bangsa. Globalisasi merupakan suatu fenomena yang berkembang cepat. Globalisasi membuat masyarakat bergerak terus dalam proses pengglobalan. Globalisasi sudah menyentuh hampir semua aspek kehidupan. Hal tersebut terjadi karena adanya kemudahan mengakses komunikasi, informasi, dan teknologi negara-negara maju. Globalisasi telah menciptakan berbagai tantangan dan permasalahan baru yang mesti dijawab dan dipecahkan. Akan tetapi, kita dapat memanfaatkan globalisasi untuk kepentingan kehidupan.

Globalisasi itu berlangsung di semua bidang seperti ideologi politik, ekonomi, pertahanan dan keamanan, serta sosial budaya. Dampak globalisasi di bidang sosial budaya sudah terasa. Kebudayaan modern dan global sudah merasuk ke dalam jiwa bangsa Indonesia. Nilai-nilai budaya lokal seperti nilai-nilai yang menyangkut etika, estetika, moral, agama, sosial, dan cara pandang diri sudah mulai terkikis, memudar, bahkan boleh jadi sudah sulit terlacak.

Jati diri bangsa atau identitas bangsa bisa meluntur karena derasnya arus globalisasi. Globalisasi telah membawa dampak negatif terhadap keutuhan dan ketahanan bangsa. Bangsa ini sudah mulai berpaling dan berkiblat kepada budaya luar. Bagaimana kelokalan kita dapat dipertahankan dan tetap eksis jika kita sendiri tidak menerapkan dan menjiwai nilai-nilai budaya lokal. Jika nilai-nilai kelokalan telah hilang, bagaimana identitas bangsa dapat dipertahankan?

Dengan demikian, diperlukan suatu upaya untuk memperkukuh nilai-nilai budaya lokal. Pemerkukuhan budaya lokal sangat diperlukan untuk mengatasi ancaman, kendala, atau tantangan yang datang dari luar yang dapat mengancam kelangsungan hidup dan eksistensi produk budaya lokal. Upaya untuk mempertahankan dan memperkukuh jati diri bangsa, salah satunya ialah melalui pengajaran bahasa. Pengajaran bahasa semestinya mengandung nilai-nilai budaya lokal. Warna lokal tentu saja mencerminkan keiindonesiaan. Pengajaran bahasa dituntut banyak mencerminkan suasana dan lokasi, falsafah, etnis, kekhasan, keunikan, atmosfer, keindahan, serta keberagaman Nusantara. Pengajaran bahasa harus mampu mengungkapkan kekayaan berbagai etnis dan menonjolkan 
khazanah kedaerahan yang tentu saja merupakan warna lokal yang termasuk identitas bangsa Indonesia.

\section{Pengajaran Bahasa dengan Karakter Kebangsaan dan Multibudaya}

Berikut ini akan dipaparkan pengajaran bahasa yang berkarakter kebangsaan dan berprespektif multibudaya.

1. Pemberian materi ajar kebahasaan yang dapat menghubungkan guru, peserta didik, dan lingkungan, misalnya peserta didik harus membuat laporan hasil wawancara terhadap guru, teman, dan masyarakat sekitar sekolah tentang "semangat kebersamaan". Dengan tema "semangat kebersamaan" dapat menumbuhkembangkan rasa kesatuan antaretnis, kepedulian, dan cinta tanah air.

2. Pemberian tugas penganalisisan dan pengapresiasian karya pengajaran bahasa yang mengandung keberagaman budaya, misalnya Robohnya Surau Kami karya A.A. Navis yang mengemukakan latar dan kekayaan budaya Minangkabau, Para Priyayi karya Umar Khayam yang mengungkapkan nuansa dan ideologi Jawa, Antologi Puisi yang ditulis oleh D. Zawawi Imron yang menyoroti kultur Madura, Upacara karya Korrie Layun Rampan yang mengungkapkan eksistensi suku Dayak, Bila Malam Bertambah Malam karya Putu Wijaya yang mengekspos kekayaan budaya Bali, dan Dim Sum Terakhir karya Clara $\mathrm{Ng}$ yang mendeskripsikan kehidupan di permukiman etnis China.

3. Dalam pembelajaran bahasa di kelas, harus terjadi interaksi antara dosen dan mahasiswa. Interaksi ialah hal saling melakukan aksi, ada hubungan timbal balik, ada komunikasi dua arah. Interaksi tentu saja bersifat dinamis, tidak statis. Dalam pembelajaran bahasa, interaksi secara verbal memang paling menonjol dan dominan.

4. Perlu adanya perancangan tugas-tugas yang memberdayakan karakter kebangsaan kepada peserta didik. Misalnya, memberikan tugas kelompok berupa laporan analisis hasil wawancara kepada pedagang kecil yang berjualan di dekat kampus. Selain peserta didik menerapkan teori teknik wawancara dan tata tulis laporan, mereka pun disentuh untuk mewujudkan care atau kepedulian kepada wong cilik. Di samping itu, pemberian tugas berupa diskusi kelompok dengan cara role play, memaksa peserta didik untuk memberdayakan karakter kebangsaan mereka. Dengan role play, mereka dapat berkreasi dalam memainkan watak, bersinergi dengan yang lain, melatih penghayatan peran, melatih daya kepekaan, dan melatih untuk mengaktualisasikan diri. Role play dalam pembelajaran bahasa, misalnya, memainkan peran sebagai mahasiswa perantauan yang berkuliah di kota besar yang diperolok-olokkan oleh teman-temannya karena menggunakan bahasa Indonesia yang berdialek daerah dang diinterferensi oleh percampuran bahasa daerah dengan bahasa Indonesia. Selain tercapainya materi ajar yaitu interferensi bahasa, juga kegiatan role play dapat menumbuhkan nilai moral yaitu menghargai sesama, kemajemukan, dan setiap pribadi memiliki keunikan. Pemberian tugas dapat dilakukan dengan memanfaatkan teknologi komputer, misalnya membuat power point yang kreatif, inovatif, dan penuh 
dengan visualisasi dan animasi ketika peserta didik mempresentasi tugas mereka.

5. Dengan pendekatan karakter kebangsaan, kita dapat mendesain aturan di kelas. Misalnya, aturan tidak boleh mencontek, aturan tidak boleh terlambat, aturan berpakaian rapi, aturan memakai sepatu, aturan tidak mengaktifkan handphone, tidak makan atau minum di kelas, berdoa sebelum dan sesudah pembelajaran, dan aturan lain yang dapat memberdayakan keterampilan karakter kebangsaan. Dalam pembelajaran bahasa, kita dapat menerapkan aturan "zona penggunaan bahasa baku, baik, dan benar" di dalam kelas jika ada yang melanggarnya boleh saja yang bersangkutan didenda (misalnya Rp5000,00 per pelanggaran dan hasilnya dapat disumbangkan untuk program adik asuh).

6. Peserta didik pun dapat mengembangkan diri melalukan kegiatan teater, unit kesenian kampus, olah raga, kelompok belajar, dan kelompok penelitian untuk meningkatkan karakter kebangsaan.

7. Untuk mendukung pembelajaran bahasa dengan pendekatan karakter kebangsaan dan pemahaman multibudaya, diadakan kegiatan-kegiatan seperti debat antarjurusan, presentasi hasil temuan penelitian oleh peserta didik di muka umum, lomba baca puisi dengan musikalisasi, penggunaan teknologi komputer dalam pembuatan poster tentang jargon/ ungkapan politik yang membangun dan mendidik bangsa, dan sebagainya.

8. Sebagai bentuk pembelajaran bahasa yang bertolok ukur kepada pendekatan karakter kebangsaan dan multibudaya secara bergilir setiap kelas paralel satu minggu sekali mengajar di sekolah dasar yang mayoritas siswanya anak dari orang tua yang berekonomi lemah. Di UK Maranatha Mata Kuliah Bahasa Indonesia setiap semester memiliki 35-40 kelas paralel. Setiap kelas mendapat kesempatan untuk berkunjung ke SD Anugerah yang terletak di depan kampus, tetapi masuk ke gang-gang sempit dan keadaannya sangat memprihatinkan. Para mahasiswa dilatih menjadi volunteer/sukarelawan untuk membantu adik-adiknya belajar bahasa Indonesia yang baik dan benar, belajar menulis, dan belajar membaca. Kepekaan peserta didik untuk berempati, merasakan kondisi yang memprihatinkan, menyaksikan secara langsung penderitaan hidup, dan mengetahui bahwa di sekitarnya ternyata ada komunitas atau kelompok yang kurang beruntung secara ekonomi akhirnya membuat peserta didik mau menghargai hidup dan kehidupan. Latihan menjadi volunteer dapat mengembangkan karakter kebangsaan dan pemahaman multibudaya peserta didik.

\section{SIMPULAN}

Berdasarkan pembahasan yang telah dilakukan, ditemukan hal-hal sebagai berikut:

1. Dalam pembelajaran bahasa, setiap bahan ajar diberi tema-tema khusus yang dapat memancing karakter kebangsaan dan pemahaman multibudaya peserta didik. 
2. Dalam pembelajaran bahasa di kelas, harus terjadi interaksi antara guru dan peserta didik.

3. Perlu adanya perancangan tugas-tugas yang memberdayakan karakter kebangsaan dan perspektif multibudaya kepada peserta didik.

4. Dengan pendekatan karakter kebangsaan, kita dapat mendesain aturan di kelas.

5. Untuk mendukung pembelajaran bahasa dengan pendekatan karakter kebangsaan, diadakan kegiatan-kegiatan yang dapat dijadikan ajang mengembangkan karakter kebangsaan.

6. Tugas guru untuk berkontribusi dalam penumbuhkembangan karakter kebangsaan dan pemahaman multibudaya peserta didik.

7. Nilai-nilai kejujuran, kesalehan, kedisiplinan, ketaatan, kepekaan, dan kebaikan harus ditanamkan secara aplikatif kepada peserta didik. Pengajaran bahasa mampu mengukuhkan nilai-nilai lokal yang positif dalam pikiran dan perasaan bangsa Indonesia.

8. Pengajaran bahasa mampu menjadi alat penapis atau penyaring pengaruh dari luar.

9. Pengajaran bahasa merupakan bagian yang sangat penting dan memegang peranan dalam peradaban bangsa apa pun di mana pun di dunia ini.

10. Anak-anak sudah harus disuguhi bacaan pengajaran bahasa yang mengandung plot dan karakter yang positif, menampilkan keragaman nilai budaya, dan disertai dengan ilustrasi yang menarik dan menawan tentang khazanah budaya lokal yang bercirikan Indonesia.

11. Guru harus jeli memilih bahan ajar yang sarat dengan nilai-nilai tradisi dan budaya lokal.

12. Kemendiknas harus mendukung upaya untuk merealisasikan pengajaran bahasa dengan karakter kebangsaan dan perspektif multibudaya dengan warna lokal dalam kurikulum pendidikan dasar, menengah, atau bahkan pendidikan tinggi.

13. Masyarakat harus diberi penyuluhan dan pencerahan bahwa perbedaan itu indah, harus dihargai, dan diterima.

14. Lewat tayangan televisi dan berita di media cetak, dapat disisipi dengan ajaran tentang toleransi, pengendalian diri, moralitas, kesantunan, dan nasionalisme dalam masyarakat.

\section{DAFTAR PUSTAKA}

Alwi, Hasan. 1999. Telaah Bahasa dan Sastra. Depdiknas: Pusat Pembinaan dan Pengembangan Bahasa.

Cultural Studies. 2000. Teori Sastra Pengantar Komprehensif. Jakarta: Jalasutra Egleton Terry.

Gulo, W. 2002. Strategi Belajar-mengajar. Jakarta: Gramedia. 
Masrukhi. 2009. "Revitalisasi Pendidikan IPS sebagai Instrumen Integrasi Nasional". Dalam Integrasi Sosial dalam Bermasyarakat majemuk pada Era Global. Universitas Negeri Semarang: Fakultas Ilmu Sosial.

Munadi, Yudhi. 2008. Media Pembelajaran, Sebuah Pendekatan Baru. Jakarta: Gaung Persada Press.

Rudy, Rita Inderawati. 2008. "Paradigma Baru Pengajaran Apresiasi Sastra Indonesia" (Makalah). Jakarta: Pusat Bahasa.

Sanjana, Wina. 2008. Perencanaan dan Desain Sistem Pembelajaran. Jakarta: Kencana Prenada Media Grup.

Srijanti dkk. 2009. Pendidikan Kewarganegaraan untuk Mahasiswa. Jakarta: Graha Ilmu.

Suprijanto. 2007. Pendidikan Orang Dewasa, dari Teori hingga Aplikasi. Jakarta: Bumi Aksara.

Susilastri, Dian. 2009. Sastra Indonesia Berwarna "Lokal": Think Globally and Act Locally. Balai Bahasa Surabaya: Pelantra. 